\title{
Determinants of dental care utilization by the adult population in Buenos Aires
}

\author{
Gustavo H Marin ${ }^{1,2}$, Pablo Urdampilleta ${ }^{2}$, Oscar Zurriaga ${ }^{3,4}$
}

\author{
${ }^{1}$ National University of La Plata, Argentina \\ ${ }^{2}$ Médicos en Prevención (MEP-ONG), Argentina \\ ${ }^{3}$ Health Inequalities Area. Centro Superior de Investigación en Salud Pública (CSISP). Generalitat Valenciana. Valencia, Spain \\ ${ }^{4}$ Associate lecturer. Preventive Medicine and Public Health Department. University of Valencia. Valencia, Spain
}

Correspondence:

Facultad de Ciencias Médicas - UNLP

Calle 60 y $120-(1900)$

La Plata-Argentina

gmarin@netverk.com.ar

Received: 06/07/2008

Accepted: 02/08/2009

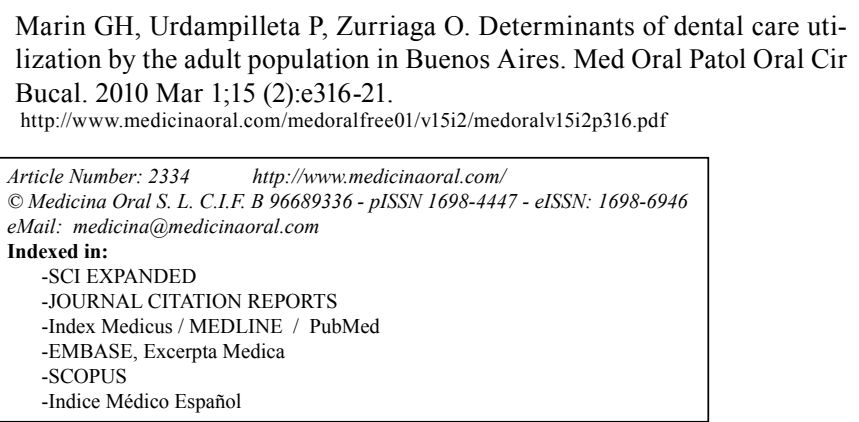

\begin{abstract}
Objective: To establish the frequency with which the general population is seen by a dentist and the variables associated with the lack of regular dental check-ups. Methods: A cross-sectional study with a descriptive and analytical phase conducted in an urban community in Argentina. A sample population was obtained by stratified method. Socioeconomic conditions (measure by UBN index), health, health coverage, level of education and location of the households with respect to the dental clinics were all taken into consideration in selecting the sample. We performed a uni-and multivariate analysis. The statistical software used was SPSS 9.0 for Windows and EpiInfo6 Version 6.0. Results: We observed significant associations between the lack of dental care and poverty levels, presence of UBN, living in the suburbs or at a remote distance from dental clinics, and the lack of health insurance. However, in a multiple regression analysis, only the geographical and socioeconomic characteristics of the respondents and their households had statistical significance. Conclusion: The section of the community that is less likely to visit their dentist regularly are those with higher socio-economic risk. Having health insurance or having a dental clinic close to home does not ensure more frequent check-ups. Given that, as demonstrated in this work, spontaneous demand for attention is extremely low, public policies should aim to include this vulnerable population in preventive and scheduled care.
\end{abstract}

Key words: Prevention, promotion, dentist, oral health, poverty. 


\section{Introduction}

Oral diseases are a problem both for individuals and for society. Oral pathology is crucial for public health because of its prevalence, the cost of treatment and its impact on the health system (1).

Although dental diseases have been reduced over the last decade in most developed countries, this decline has not been seen in developing countries. There is some evidence that economic (2-4), racial (5), and age $(6,7)$ variables affect access to health checks.

As a result, some countries have specific strategies in these areas. In Brazil, for example, the inclusion of oral health teams as part of the "Estratégia de Saúde da Familia" assures access to oral care for socio-economically disadvantaged families. However, in other Latin American countries, oral health has not seen much progress and is generally regarded as an aesthetic improvement or a luxury good when compared to the other great problems which afflict their inhabitants (8). Oral diseases are often linked to malnutrition or systemic diseases $(3,4)$.

Many of the frequent oral diseases are preventable with good dental advice and a change of habits in food and hygiene (9-11).

The value of prevention in oral health has been demonstrated by Denmark's National Program (12). Promotional actions related to oral health are essential and are one of the tools needed to reach the World Health Organization (WHO) goals for 2020 (13).

A routine dentist consultation (every 6 months for children, teenagers and the elderly or each year for healthy adults) $(5,14)$ avoids many of the aforementioned oral pathologies.

Regular visits to the dentist are inversely related to the presence of caries, teeth restoration, dental extraction needs or gum pathology $(15,16)$.

Generally speaking, routine consultations are seen in the pediatric population and are less common for adults.

The organization of oral health care in Argentina is mainly on demand, and consultations are mostly made when there is some kind of dental problem that warrants attention.

Dental care depends on the type of health insurance. Private or worker's health insurance companies assign to their policyholders an oral health care institution or dentist's office if necessary or if their affiliates demand a consultation. However, a cash payment is always needed to cover a percentage of the professional's fee. In the cases where specific health coverage is lacking, the state provides inhabitants with free dental consultation in the state's institutions. Local governments (municipios) offer primary health care services like promotional or preventative actions or for basic attention (mostly dental extractions). However, only $60 \%$ of primary health care centers have a dentist or dental chair. If consultations require more complex services, the state government (province) offers its public hospitals.

The waiting time for consultations is extremely long and by the time they arrive it is often too late or the problem has gone.

Both in the private and state system, dental consultations are always motivated by the applicants themselves (spontaneous demand health care). No scheduled visits are urged by the funders.

It is assumed therefore that there is a problem of accessibility in a population with socio-economic disadvantages and without specific health coverage. Notably, this information has not yet been focused on Argentina where there may be other barriers that impede putting effective dental controls into practice.

In order to establish the degree of consultations for routine dental check-ups of adults in an urban community in Argentina and the variables associated with them, this prospective study is proposed.

\section{Materials and Methods}

This is a cross-sectional study consisting of two phases (descriptive and analytical) with a quantitative approach. Because the Argentine population is mostly urban and $40 \%$ of the country's population lives in the province of Buenos Aires, this study was located in the capital of this province (La Plata) which, according to the National Institute of Statistics and Census (INDEC) (2001 census) data, is a faithful exponent (17) which mixes the socio-economic characteristics of most cities of the country.

In collaboration with the State Statistics and Census Direction of Buenos Aires, a representative random stratified sample from the municipality of La Plata homes chosen by their geographic area and social level was made. The sample size was calculated according to routine control theory, with a confidence of $95 \%$ (alpha error $=5 \%$ ) and an accuracy of $5 \%$ in a theoretical minimum of 994 dwellings, surveying one representative adult in each home (the first adult to open the door of the home during the visit) out of a total of 596,000 citizens of the municipality, using the following formula:

$$
\mathrm{n}=\frac{\mathrm{N} \cdot \mathrm{Z}^{2} \cdot \mathrm{p}(1-\mathrm{p})}{\mathrm{d}^{2} \cdot(\mathrm{N}-1)+\mathrm{Z}^{2} \cdot \mathrm{p}(1-\mathrm{p})}
$$

where $\mathrm{n}$ is the sample size, $\mathrm{N}$ the total population, $\mathrm{Z}$ the value of $z$ for confidence level ( 1 - alpha), $p$ the expected proportion in the population and $\mathrm{d}$ the absolute accuracy.

The unit of analysis was the "member" of the household through which the survey would be conducted. The sample selection method for those "members" identifi- 
cation was a three-stage randomized approach: the first stage involved radius census selection, the second selection was dedicated to selecting the "squares" (tables of 100 meter blocks per side) within the selected radius, and houses and homes of those squares were identified during the third stage of the sample selection.

Aspects considered for sample stratification processes were:

- "Unsatisfied Basic Needs": composed of socio-economic indicators incorporating: house overcrowding (three or more family members per room); lack of sewerage services; unstable house construction; illiteracy among a member of that family; or children in the house that do not attend school.

- Household income.

- Geographical proximity of the house surveyed to a local health center (LHC).

All this data was obtained from the last national census.

The criteria for including participants in the study were: age (persons who at the time of the survey were 18 years or older); persons who come from the area selected for the study or who have lived in the region for over a year and the voluntary acceptance of participation.

Selection of Variables:

The dependent variable chosen was the frequency of query to a dentist in the last 12 months at the time of the survey.

The independent variables were related to:

1. Demographic aspects: gender and age (individuals older than 18 years according to the age document shown by the respondent at the time of responding to the survey);

2. Socio-cultural aspects:

- Level of poverty: conceptually defined as the level of income able to access the basic basket of goods and services at the time at which the selected home was first visited;

- Member of households with or without unsatisfied basic needs (UBN) as established above by the guidelines provided by INDEC (17);

- Level of education of the members of the house: defined as the maximum level reached by the respondent; this may be the level of primary schooling (6 years of basic education), secondary (6 years of instructional media) and College or University;

- Employment: considering the categories of employed, unemployed or under-employed according to the guidelines established by INDEC (17);

- Social assistance: Presence or absence of the benefit of a government social assistance program at the time of the survey;

3. Issues related to accessibility to health care: provided through:

- Health Coverage: assessed by whether person is or is not relying on health insurance (Health insurance or Pre-payment) to cover health care needs;

- Distance between the home registered for survey and local health care center (LHC) establishing "proximity" if the home was less than 1000 meters from the LHC.

Data Collection and Information Sources:

Each respondent answered two polls: a socio-economic survey and a health survey about dental consultation.

The strategy of data analysis included:

Descriptive analysis, benchmarking, and analysis of associations using univariate and multivariate models. This analysis was performed for both males and females. The analysis was made using SPSS program version 9.0 for Windows, the database program for Public Health Statistics and EpiInfo6 version 6.0 (Center for Disease Control and Prevention / World Health Organization).

The values of quantitative variables were summarized using the average as a measure of central tendency and standard deviation as a measure of dispersion ( \pm SD). The values of qualitative variables were expressed as a percentage $(\%)$.

We used the $\chi^{2}$ test with significance level of $5 \%$ to establish statistical associations between the dependent variable (dental) and independent variables (age, sex, geographic area of residence, having specific health coverage, medical care and socio-economic status).

For another analysis between those respondents that did consult their dentists during the last year and those that didn't, the $\chi^{2}$ test was used in order to demonstrate differences among proportions of variables related to social, demographic, geographic and health aspects, and the ANOVA test for differences between mean parametric distributions for the following variables: age, level of employment, social assistance plan, level of income below the poverty line and UBN.

For association studies, simple (univariate) between the dependent and independent variables, Odds Ratio was used. Several logistic regression models with the dependent variable (dental consultation) were carried out, incorporating one by one the parameters evaluated in the univariate model. With the regression coefficients obtained, ratio of cross products were estimated (Odds Ratio, 95\% $\mathrm{CI})$ as the following formula: Odds ratio = ex; IC 95\%= $\mathrm{e}^{\left(\beta \pm \text { st.e*1.96) }^{*}\right.}$ where $\beta$ is the estimated of logistic regression; St-e is the standard error; and 1.96 is the $Z$ value (with a confidence level of $95 \%$ ).

\section{Results}

1,122 individuals were surveyed in 1,400 homes visited $(80.14 \%$ of voluntary survey acceptance). Characteristics of the study population are shown in Table I. These characteristics differ significantly according to the place of residence of the study population, establishing two distinct groups: those living in the downtown area (urban area) and those who do not (suburbs 
Table 1. Population characteristics according to place of residence.

\begin{tabular}{|c|c|c|c|c|}
\hline Characteristics & $\begin{array}{c}\text { Population Sample } \\
\text { n: } 1136\end{array}$ & $\begin{array}{c}\text { Urban zone } \\
\text { n: } 570\end{array}$ & $\begin{array}{c}\text { Suburbs } \\
\text { n: } 566\end{array}$ & $P$ value \\
\hline $\begin{array}{c}\text { Age } \\
\text { (years) } \\
\text { (average } \pm \text { DS) }\end{array}$ & $42.97 \pm 19.0$ & $44.2 \pm 13.1$ & $41.7 \pm 18.6$ & 0.009 \\
\hline $\begin{array}{c}\text { Age (groups) } \\
18-29 \\
30-49 \\
50-69 \\
>70 \\
(\%)\end{array}$ & $\begin{array}{c}29.9 \\
35.7 \\
28.9 \\
5.5\end{array}$ & $\begin{array}{l}28.9 \\
31.7 \\
29.2 \\
10.2\end{array}$ & $\begin{array}{c}33.2 \\
31.1 \\
28.4 \\
7.3\end{array}$ & $\begin{array}{l}0.03 \\
\mathrm{~N} / \mathrm{S} \\
\mathrm{N} / \mathrm{S} \\
0.01\end{array}$ \\
\hline $\begin{array}{c}\text { Female } \\
\text { Male } \\
(\%)\end{array}$ & $\begin{array}{l}61.3 \\
38.7\end{array}$ & $\begin{array}{l}60.5 \\
39.5\end{array}$ & $\begin{array}{l}58.5 \\
41.4\end{array}$ & $\begin{array}{l}\mathrm{N} / \mathrm{S} \\
\mathrm{N} / \mathrm{S}\end{array}$ \\
\hline $\begin{array}{c}\text { Low income population } \\
(\%)\end{array}$ & 32.6 & 14.8 & 39.5 & $<0.001$ \\
\hline $\begin{array}{l}\text { UBN Population } \\
(\%)\end{array}$ & 21.3 & 4.3 & 36,9 & $<0.001$ \\
\hline
\end{tabular}

The values found are given in percentages followed by one standard deviation for all variables (except for the age ranges which were expressed as percentage of individuals belonging to that age group compared to all of the individuals in the sample). The degree of significance is established by comparing the center with the suburbs $(95 \%)$. UBN: Unsatisfied Basic Needs (indicator of structural poverty).

or suburban area). Regarding health coverage, $61.9 \%$ of the individuals surveyed had specific health insurance while $39.1 \%$ had only the public state health system to rely on for their health care. Socio-economic data of households and individuals surveyed showed the mean of respondents with UBN (17) was $21.3 \pm 16.6$ and large differences between the geographic areas studied were seen (Table 1).

Regarding the income level of respondents, it was observed that $16.3 \%$ of their incomes were less than 200 Euros per month (7.7\% lower than 100), and 17.2\% between $201 €$ and $300 €, 23.1 \%$ between $301 €$ and $401 €$, and $25.3 \%$ between $401 €$ and $500 €, 11.7 \%$ between 501 $€$ and $600 €$ and $6.5 \%$ for income over $600 €$.

Among those respondents with incomes below $200 \mathrm{Eu}-$ ros a month $(\mathrm{n}=214)$, a quarter of them consulted a dentist in the past year, while among those whose salary is greater $(n=908)$, annual consultations were conducted in $67.4 \%$ of cases $(p<0.001)$.

Only a third from the population with unsatisfied basic needs $(n=176)$, visited their dentist during the last year, while among people without UBN $(n=959)$, the consultation rate in the twelve month period was $62.1 \%$ $(\mathrm{p}<0.001)$.

In those individuals with a medium educational level (high school), annual dental checks were done in $61 \%$ of cases versus $46 \%$ for those who did not reach that level ( $\mathrm{p} 0.004$ ), or compared to $18 \%$ of respondents who did not complete the baseline primary educational level $(\mathrm{p}<0.001)$.

With regard the frequency of consultations according to geographical area, it was noted that inhabitants of downtown urban areas had consulted dentists in $69.6 \%$ of cases while the percentage of annual consultations for the people living in the suburbs was statistically lower (27.1\%) ( $\mathrm{p}<0.001)$. (Fig. 1).

Health insurance slightly increased the level of consultations compared to those respondents with no insurance except public health care programs.

The respondents' addresses regarding the nearest health facility had no affect on the level of visits to the dentist, so the proximity or remoteness of the house had no relation to the level of consultation $(49.8 \%$ vs. $41.6 \%$ respectively) ( $\mathrm{p}$ 0.08).

In the multivariate analysis and logistic regression model, health insurance coverage, or the geographic location of the houses surveyed regarding the location of the center for dental care, did not retain their statistical significance (Table 2). Only UBN, the income level below the basic family basket, the educational level and living in the suburbs retained their statistical significance (Table 2).

\section{Discussion}

Adverse health conditions found in many communities in developing countries usually delay government's po- 


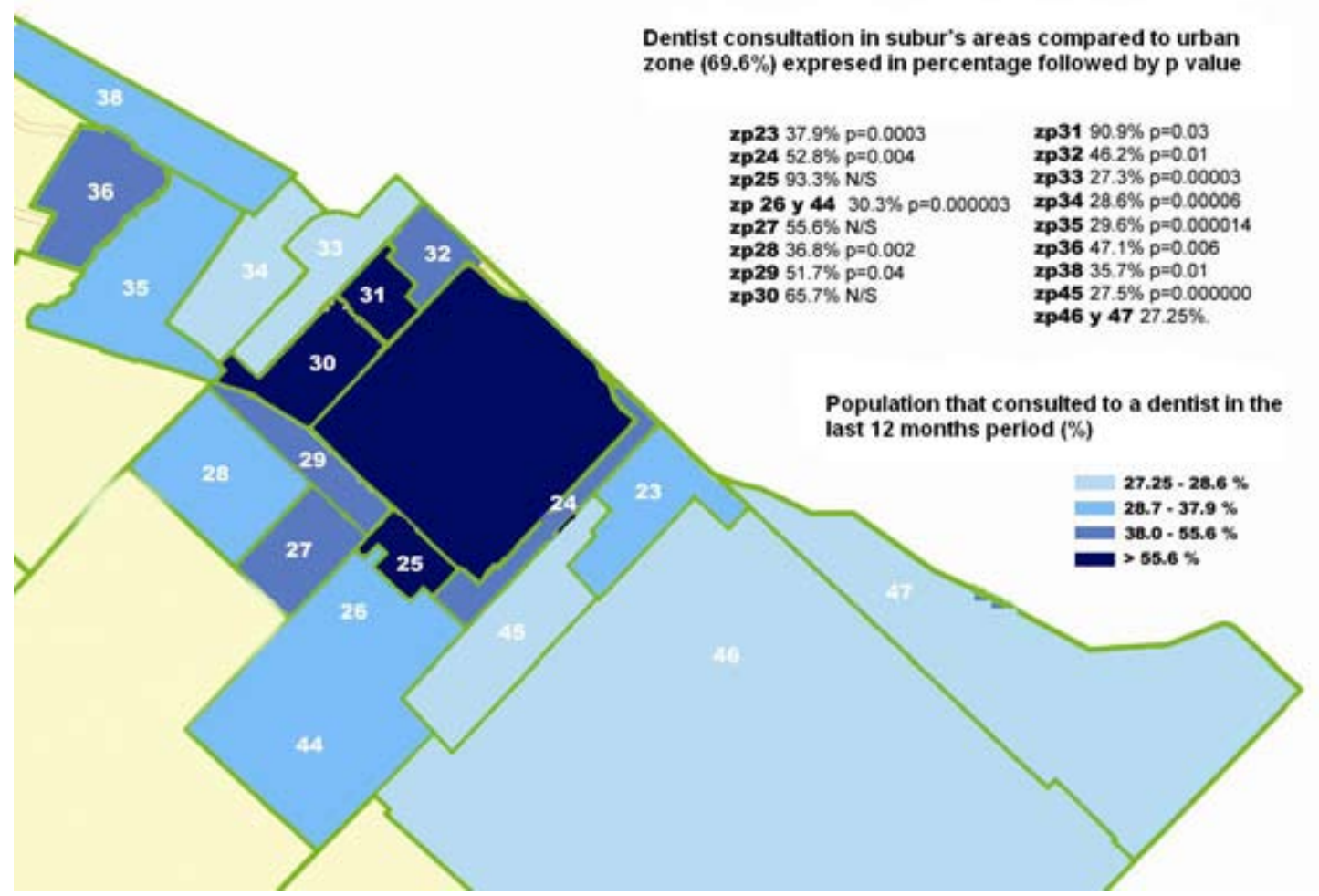

Fig. 1. Dentist consultation in subur's areas compared to urban zone.

Table 2. Association between dental consultations and socio-demographic conditions.

\begin{tabular}{|l|c|c|c|}
\hline \multicolumn{1}{|c|}{ Variable } & $\begin{array}{c}\text { Odds } \\
\text { Ratio }\end{array}$ & IC 95\% & p Value \\
\hline \multicolumn{4}{|c|}{ Analysis of dental associations with the following independent variables: } \\
\hline Income $<200 €$ & 2.9 & $2.2-4.7$ & $<0.001$ \\
\hline UBN & 2.5 & $1.9-4.9$ & $<0.001$ \\
\hline Residence in urban zones & 0.8 & $0.3-1.4$ & $<0.001$ \\
\hline Relying on health coverage & 0.6 & $0.5-0.8$ & 0.006 \\
\hline $\begin{array}{l}\text { Geographical location of the house } \\
\text { surveyed to a local health center }\end{array}$ & 0.7 & $0.2-0.9$ & 0.002 \\
\hline \multicolumn{3}{|c|}{ Multivariate analysis: Multiple logistic regression model } \\
\hline UBN & 2.9 & $1.3-3.7$ & $<0.001$ \\
\hline Income $<€$ 200 & 2.4 & $1.2-3.1$ & $<0.001$ \\
\hline Residence in the suburbs & 1.9 & $1.2-3.6$ & $<0.001$ \\
\hline
\end{tabular}

UBN: unsatisfied basic needs (a poverty indicator). 
licies concerning oral health care. Preventive actions can substantially improve oral cavity conditions in order to avoid local or systemic problems in the future. However, these results are only observed over the long term, far beyond the period of political management. Current proposals for dental health care are mostly due to already existing oral health problems. More preventive actions are necessary in all Latin American countries Assessing the level of regular dental consultations conducted by community members and the variables associated with the lack of check-ups provides some of the essential information necessary to allow alternative proposals for changing the current situation.

This study was designed with special attention paid to ensuring that the selection of homes in the housing survey reflected the socio-economic and health status of the community and that a representative sample from this population was obtained. This fact, associated with a high response rate to the survey, gives greater validity to the results obtained. However, there are some elements which have not been taken into account in the design of the study and which could in some way modify the frequency of dental check-ups, such as cultural aspects, habits (smoking and other addictions), the presence of other systemic diseases etc.

There exists a common reality shared by many regions in Latin America that installs the habit of routine consultations with physicians and dentists as a preventative measure during childhood. However, during adulthood these check-ups are often delayed, especially the dental visit. Among adults, the most common cause for a professional consultation with a dentist is a sudden pain caused by dental or periodontal disease. Therefore, it is necessary to install in this adult group the same routines already accepted for earlier ages. Knowing the reasons why such tests are not performed in adulthood and identifying those who have the greatest access barriers to complying with these needed routine visits, may help to encourage adoption of the needed policies.

The present study helps to identify those vulnerable groups and finds that one of the major causes for delaying a routine dental check-up is linked to the socioeconomic conditions of the population.

In conclusion, people living in the suburbs, who failed to obtain a high school educational level, with the lowest socio-economic status and with incomes below a basic family basket that allows the acquisition of a minimum amount of food and clothing, reduce their periodic dental consultations in comparison with those adults who live downtown and have a higher socio-economic level.

Therefore, due to this lower rate of dental check-ups among the unprotected population, it would be wise for local governments to take a proactive approach and direct health policies towards encouraging oral disease prevention through regulated annual dental consultations by the said population.

\section{References}

1. Bajwa A, Watts TL, Newton JT. Health control beliefs and quality of life considerations before and during periodontal treatment. Oral Health Prev Dent. 2007;5:101-4.

2. Andersen R, Newman JF. Societal and individual determinants of medical care utilization in the United States. Milbank Mem Fund Q Health Soc. 1973;51:95-124.

3. Almerich Silla JM, Montiel Company JM. Oral health survey of the child population in the Valencia Region of Spain (2004). Med Oral Patol Oral Cir Bucal. 2006;11:E369-81.

4. Manski RJ, Moeller JF, Maas WR. Dental services. An analysis of utilization over 20 years. J Am Dent Assoc. 2001;132:655-64.

5. Gilbert GH, Duncan RP, Heft MW, Coward RT. Dental health attitudes among dentate black and white adults. Med Care. 1997;35:25571

6. Kiyak HA. An explanatory model of older persons' use of dental services. Implications for health policy. Med Care. 1987;25:936-52.

7. Kiyak HA, Reichmuth M. Barriers to and enablers of older adults' use of dental services. J Dent Educ. 2005;69:975-86.

8. Cleaton-Jones P, Fatti P, Bönecker M. Dental caries trends in 5- to 6-year-old and 11- to 13-year-old children in three UNICEF designated regions--Sub Saharan Africa, Middle East and North Africa, Latin America and Caribbean: 1970-2004. Int Dent J. 2006;56:294300.

9. Schwarz E. Changes in utilization and cost sharing within the Danish National Health Insurance dental program, 1975-90. Acta Odontol Scand. 1996;54:29-35.

10. Guilbert JJ. The world health report 2002 - reducing risks, promoting healthy life. Educ Health (Abingdon). 2003;16:230.

11. Petersen PE. The World Oral Health Report 2003: continuous improvement of oral health in the 21st century--the approach of the WHO Global Oral Health Programme. Community Dent Oral Epidemiol. 2003;31 Suppl 1:3-23.

12. Holm-Pedersen P, Vigild M, Nitschke I, Berkey DB. Dental care for aging populations in Denmark, Sweden, Norway, United kingdom, and Germany. J Dent Educ. 2005;69:987-97.

13. Morgan MV, Wright FA, Lawrence AJ, Laslett AM. Workforce predictions: a situational analysis and critique of the World Health Organisation model. Int Dent J. 1994;44:27-32.

14. Redmond CA, Hamilton FA, Kay EJ, Worthington HV, Blinkhorn AS. An investigation into the value and relevance of oral health promotion leaflets for young adolescents. Int Dent J. 2001;51:164-8.

15. Jones K, Tomar SL. Estimated impact of competing policy recommendations for age of first dental visit. Pediatrics. 2005;115:90614.

16. Plutzer K, Spencer AJ. Efficacy of an oral health promotion intervention in the prevention of early childhood caries. Community Dent Oral Epidemiol. 2008;36:335-46.

17. Etchegoyen G, Paganini JM, Consorcio Interdisciplinario Multicéntrico Para Estudio de la Inequidad en Salud. [The relationship between socioeconomic factors and maternal and infant health programs in 13 Argentine provinces]. Rev Panam Salud Publica. 2007;21:223-30 